\title{
Prevalence of Sexually Transmitted Diseases Among Latino Immigrant Day Laborers in an Urban Setting-San Francisco
}

\author{
WILLIAM WONG, MD, ${ }^{\dagger}{ }^{\dagger} \mathrm{JOHN}$ A. TAMBIS, BS, ${ }^{\dagger}$ MARIA T. HERNANDEZ, MPH, ${ }^{\dagger}$ JANICE K. CHAW, MPH, ${ }^{\dagger}$ AND \\ JEFFREY D. KLAUSNER, MD, MPH, ${ }^{\dagger}$
}

\begin{abstract}
Background: Although rural Latino migrant laborers have been identified as a group at-risk for acquiring HIV, few studies have examined transmitted diseases (STDs) in urban, Latino migrant laborers.

Goal: To assess the prevalence of STDs in a sample of urban, migrant day laborers in San Francisco.

Study Design: A convenience sample of participants in the Day Laborer Project of the San Francisco Department of Public Health was screened for STDs from September 1994 to January 2001. Screening included serologic tests for syphilis and nucleic acid amplification tests for gonorrhea and chlamydia.

Results: A total of 292 clients participated in the screening program. All participants were male, Latino, and recent immigrants. Of the $\mathbf{2 3 5}$ persons screened for syphilis, secondary syphilis was diagnosed in one $(0.4 \%)$ participant. Of the 198 persons screened for gonorrhea and chlamydia, $1(0.5 \%)$ had gonorrhea and $7(3.5 \%)$ had chlamydia.

Conclusion: Urban Latino migrant day laborers are a population at-risk for infection with STDs. Community-based STD screening programs might be an effective way to detect STDs in this population.
\end{abstract}

ESTIMATES OF THE PREVALENCE of sexually transmitted diseases (STDs) among Latino migrant laborers in urban areas are limited. STD prevention in migrant populations is of particular interest because foreign-born Latinos have been identified as having high incidence rates of STDs, HIV, and AIDS in the United States. ${ }^{1-4}$ Because the presence of ulcerative and nonulcerative STDs facilitates the acquisition and transmission of HIV, a better understanding of STD epidemiology is critical to HIV prevention in at-risk populations. ${ }^{5-8}$

Because STDs and HIV share similar social and behavioral factors that lead to disease transmission, the presence of high rates of STD in certain populations might identify populations vulnerable to HIV infection. ${ }^{9}$ In a study involving 176 northern California Mexican farm workers, Lopez and Ruiz ${ }^{10}$ found a $0 \%$ HIV prevalence, two active cases of syphilis, and a 9\% lifetime history of STDs. Other studies document higher rates of STDs and unsafe sex practices in rural migrant farm workers, warranting prevention

The authors thank Charlotte Kent, MPH, and Veronica Davila of the San Francisco Department of Public Health; German Martinez of the Day Laborer Program; and Ronald Moolenaar, MD, MPH, of the Epidemiology Program Office, Centers for Disease Control and Prevention, for their assistance in preparing and editing this article.

Reprint requests: William Wong, MD, STD Prevention and Control Services, San Francisco Department of Public Health, 1360 Mission Street, Suite 401, San Francisco, CA 94103. E-mail: will.wong@sfdph.org

Received December 30, 2002, revised March 5, 2003, and accepted March 14, 2003.

DOI: 10.1097/01.OLQ.0000079522.04451.CB
From the *Epidemic Intelligence Service, State Branch, Division of Applied Public Health Training, Epidemiology Program Office, Centers for Disease Control and Prevention; and ${ }^{\dagger}$ Sexually Transmitted Disease Prevention and Control Services, Population Health and Prevention Division, Department of Public Health, City and County of San Francisco, California

efforts within this population.4,11,12 Low socioeconomic status, education level, and literacy ${ }^{13}$ are barriers to healthcare access for Latino migrant workers. Low levels of condom use, poor safe-sex knowledge, and high-risk sexual behaviors ${ }^{14,15}$ contribute to the potential for STD acquisition.

Providing STD screening services in community settings rather than traditional healthcare settings might be an effective means of reaching immigrant Latinos who are comparatively less likely to access healthcare services than United States-born Latinos and whites. ${ }^{16}$ The use of DNA amplification urine testing for Chlamydia trachomatis and Neisseria gonorrhoeae has facilitated the ease of testing persons for STDs in nonhealthcare settings. ${ }^{17-19}$ Our study estimated the prevalence of gonorrhea, chlamydia, and syphilis in a convenience sample of urban, migrant day laborers in San Francisco.

\section{Methods}

The Day Laborer Project of the San Francisco Department of Public Health STD Prevention and Control Services was a screening program that served clients of a local day laborer job-placement agency. The agency provided employment for approximately 1200 persons per year, including a core group of persons who relied on the agency to provide continuous year-round employment. Agency clients arrived daily to receive available short-term manual labor work assignments in the restaurant or construction industries. Laborers were primarily monolingual, Spanish-speaking men who lived in the United States for less than 1 year and resided in San Francisco.

Project outreach workers offered STD counseling and testing services one day per week on-site to agency clients. Participation in the project was voluntary, and food vouchers, when available, were offered as incentives to clients to undergo screening. Staff provided STD education and testing services to anyone who agreed to participate in the screening program

From September 1994 to January 2001, we invited clients of the Day Laborer Program to participate in confidential STD screening services to obtain a convenience sample for our study. Written consent from the client was not required, but screening was per- 
TABLE 1. Demographic Characteristics of a Sample of Migrant Day Laborers

\begin{tabular}{|c|c|}
\hline Characteristic & Number (\%) \\
\hline \multicolumn{2}{|l|}{ Gender } \\
\hline Male & $291(100)$ \\
\hline \multicolumn{2}{|l|}{$\operatorname{Age}^{\star}(\mathrm{y})$} \\
\hline$\leq 24$ & $86(30)$ \\
\hline $25-30$ & 67 (23) \\
\hline $31-44$ & $109(38)$ \\
\hline$\geq 45$ & $27(9)$ \\
\hline \multicolumn{2}{|l|}{ Ethnicity } \\
\hline Hispanic/Latino & $291(100)$ \\
\hline \multicolumn{2}{|l|}{ Primary language } \\
\hline Spanish & $291(100)$ \\
\hline \multicolumn{2}{|l|}{ Country of origin } \\
\hline Mexico & $164(56)$ \\
\hline Honduras & $25(9)$ \\
\hline El Salvador & 22 (8) \\
\hline Guatemala & $18(6)$ \\
\hline Nicaragua & $14(5)$ \\
\hline Cuba & $11(4)$ \\
\hline Other ${ }^{\dagger}$ & $7(1)$ \\
\hline Unknown & $30(10)$ \\
\hline \multicolumn{2}{|l|}{ Sexual orientation } \\
\hline Heterosexual & $175(60)$ \\
\hline Gay/bisexual & $7(2)$ \\
\hline Unknown/refused & $109(37)$ \\
\hline \multicolumn{2}{|l|}{ Place of residence } \\
\hline Shelter & $143(49)$ \\
\hline House/apartment & 81 (28) \\
\hline Homeless & $46(16)$ \\
\hline Hotel & $5(2)$ \\
\hline Unknown/refused & $16(5)$ \\
\hline
\end{tabular}

${ }^{*}$ Ages were unavailable for two participants.

${ }^{\dagger}$ Other countries of origin included Brazil, Colombia, Peru, Puerto Rico, and Venezuela.

formed after obtaining verbal consent. Syphilis screening occurred throughout this entire period, whereas gonorrhea and chlamydia screening began in August 1998. Blood samples were tested for syphilis using the VDRL test, and reactive specimens were confirmed by Treponema pallidum particle agglutination (TP-PA, Fujirebio Diagnostics, Inc., Malvern, PA). Urine samples were tested for $C$ trachomatis and $N$ gonorrhoeae using ligase chain reaction (LCx, Abbott Laboratories, Abbott Park, IL) at the San Francisco Department of Public Health Laboratory. Clients who tested positive for syphilis were educated and referred to the local STD clinic for further evaluation and treatment; those who tested positive for $C$ trachomatis and $N$ gonorrhoeae were counseled and offered field-delivered medication or referral. We compared age characteristics of patients with chlamydial infection using the $t$ test for significance.

\section{Results}

A total of 291 clients participated in this study (Table 1). All participants were male, Latino, and originated from Mexico or South and Central America. The mean (SD) age was 30.2 (10.0) years. The majority of the participants were homeless and resided in shelters, on the streets, or with friends.

Among the 235 participants screened for syphilis, 1 (0.4\%) case of secondary syphilis was identified; no cases of primary syphilis were found. The case patient was a 17-year-old male participant, and was referred, evaluated, and subsequently treated for syphilis infection at the local STD clinic.
Among the 198 participants screened for gonorrhea and chlamydia, we identified 1 case of gonorrhea $(0.5 \%)$ and 7 cases of chlamydia $(3.5 \%)$. The mean (SD) age of participants who were screened for gonorrhea and chlamydia was 29.7 (9.6) years. The case patient with gonorrhea was a 32-year-old man. Among participants identified with chlamydial infection, the mean (SD) age was 26.4 (7.2) years versus 29.6 (9.9) years for persons without chlamydial infection $(P=0.4)$. Chlamydial infection was not associated with any particular country of origin, sexual orientation, or place of residence. Staff provided cefixime $(400 \mathrm{mg})$ to the person identified with gonococcal infection and azithromycin $(1 \mathrm{~g})$ to five persons identified with chlamydial infection, as single oral dose field-delivered therapy. Two additional persons identified with chlamydial infection were referred to the local STD clinic and treated with doxycycline (100 mg twice a day for 7 days). None of the 123 participants screened for syphilis, gonorrhea, and chlamydia was infected with more than one STD.

\section{Discussion}

This study indicates that screening for STDs at the Day Laborer Program of the San Francisco Department of Public Health was feasible and identified males with STDs from a sample of Latino immigrant urban day laborers. The program identified and referred for treatment one participant with secondary syphilis, an infectious form of the disease. The prevalence of infectious syphilis was less than that found in earlier studies of rural migrant farmworkers that reported syphilis infection rates of $5.6 \%$ to $16.0 \% .^{2,4,20}$ Nonetheless, comparison with these studies might not be warranted because of differences in populations and study settings. When compared with prevalence estimates of STDs among men in San Francisco, the prevalence of gonorrhea in our sample was similar $(0.5 \%$ versus $0.45 \%)$, whereas the prevalence of chlamydia $(3.5 \%$ versus $0.3 \%$ ) and infectious syphilis $(0.4 \%$ versus $0.013 \%)$ was greater. ${ }^{21}$ Chlamydial infection was more common in younger males, but this difference was not statistically different. Results suggest that community-based STD screenings might be useful for identifying STDs among populations at risk, such as urban Latino immigrant workers. Community-based screening programs might facilitate entry into more traditional healthcare settings, such as full-service clinics for clients requiring additional testing or evaluation by a clinician.

Results from this study should be interpreted cautiously with several limitations in mind. Because this cross-sectional study relied on convenience sampling at one work program in San Francisco, sampling bias might limit the generalizability of our findings to other urban migrant labor populations. Participants screened might have had symptoms or histories suggestive of STDs and thus would be expected to have a higher prevalence of disease than persons without symptoms or histories. Additional demographic factors, sexual history, and physical signs and symptoms were not collected as part of the screening assessment, thereby limiting further description of risk in this population. Also, our findings might be relevant only to California and the western United States as STD prevalence rates among western stream migrants might differ from the prevalence rates of eastern stream migration populations. ${ }^{2,3,4,10,15,20}$

Additional research to improve the estimates of STD prevalence among urban migrant laborers is needed to evaluate the disease burden and to establish specific targets for disease control and prevention efforts. Future research that examines the social and behavioral characteristics of urban migrant populations might reveal a greater understanding of the migration-related and cultural factors that govern risk in this marginalized population. 


\section{References}

1. Egan J. HIV risk 10 times higher for migrant farmworkers. Public Health Rep 1994; 109:459

2. Centers for Disease Control and Prevention. HIV seroprevalence in migrant and seasonal farmworkers-North Carolina, 1987. MMWR Morb Mortal Wkly Rep 1988; 37:517-519.

3. Castro KG, Lieb S, Jaffe HW, et al. Transmission of HIV in Belle Glade, Florida: lessons for other communities in the United States. Science 1988; 239:193-197.

4. Centers for Disease Control and Prevention. HIV infection, syphilis, and tuberculosis screening among migrant farm workers-Florida, 1992. MMWR Morb Mortal Wkly Rep 1992; 41:723-724.

5. Centers for Disease Control and Prevention. HIV Prevention through early detection and treatment of other sexually transmitted diseases-United States. MMWR Morb Mortal Wkly Rep 1998; 47:RR12.

6. Fleming DT, Wasserheit JN. From epidemiological synergy to public health policy and practice: The contribution of other sexually transmitted diseases to sexual transmission of HIV infection. Sex Transm Infect 1999; 75:3-17.

7. Grosskurth H, Mosha F, Todd J, et al. Impact of improved treatment of sexually transmitted diseases on HIV infection in Ural Tanzania: randomized controlled trial. Lancet 1995; 346:530-536.

8. Wawer MJ, Sewankambo NK, Serwadda D, et al. Control of sexually transmitted diseases for AIDS prevention in Uganda: a randomized community trial. Rakai Project Study Group. Lancet 1999; 353:525535 .

9. Aral SO. Sexually transmitted diseases: magnitude, determinants and consequences. Int J STD AIDS 2001; 12:211-215.

10. Ruiz JD, Da Valle L, Junghkeit M, Mobed K, Lopez R. Seroprevalence of HIV and syphilis and assessment of risk behaviors among migrant and seasonal farmworkers in Northern California. Sacramento, CA: Office of AIDS, California Department of Health Services, 1997.

11. Brammeier M, Gould G, Miller J, Chow J, Lighthall D, Bolan G. Sexually transmitted disease risk behaviors among California agri- cultural workers: results from a population-based survey (abstract no. 131). Presented at the National STD Prevention Conference. San Diego, CA, 2002.

12. Bertolli J. Prevention and control of sexually transmitted diseases among migrant farmworkers. Public Health Rep 1993; 108:177-178.

13. Rust GS. Health status of migrant farmworkers: a literature review and commentary. Am J Public Health 1990; 80:1213-1217.

14. Organista KC, Balls Organista P, Garcia de Alba G JE, Castillo Moran MA, Carillo H. AIDS and condom-related knowledge, beliefs, and behaviors in Mexican migrant laborers. Hispanic J Behav Sci 1996; 18:392-406.

15. Organista KC, Balls Organista P. Migrant laborers and AIDS in the United States: a review of the literature. AIDS Educ Prev 1997; 9:83-93.

16. Macias E P, Morales L S. Utilization of health care services among adults attending a health fair in South Los Angeles County. J Community Health 2000; 25:35-46.

17. Jones CA, Knaup RC, Hayes M, Stoner BP. Urine screening for gonococcal and chlamydial infections at community-based organizations in a high-morbidity area. Sex Transm Dis 2000; 27 : $146-151$.

18. Noren L, von Krogh GV, Bondesson L, Nohlgard C, Grillner, L. Potential public health benefits from testing with Chlamydia trachomatis PCR technique on first void urine in men. Acta Derm Venereol 1998; 78:63-66.

19. Reitmeijer CA, Yamaguchi KJ, Ortiz CG, et al. Feasibility and yield of screening urine for Chlamydia trachomatis by polymerase chain reaction among high-risk male youth in field-based and other nonclinic settings: a new strategy for sexually transmitted disease control. Sex Transm Dis 1997; 429-435.

20. Jones JL, Rion P, Hollis S, Longshore S, Leverette WB, Ziff L. HIV-related characteristics of migrant workers in rural South Carolina. South Med J 1991; 84:1088-1090.

21. STD Prevention and Control Services. San Francisco sexually transmitted disease annual summary, 2000. San Francisco, CA: San Francisco Department of Public Health, November 2001. 